\title{
Obituary for Assa Reichert
}

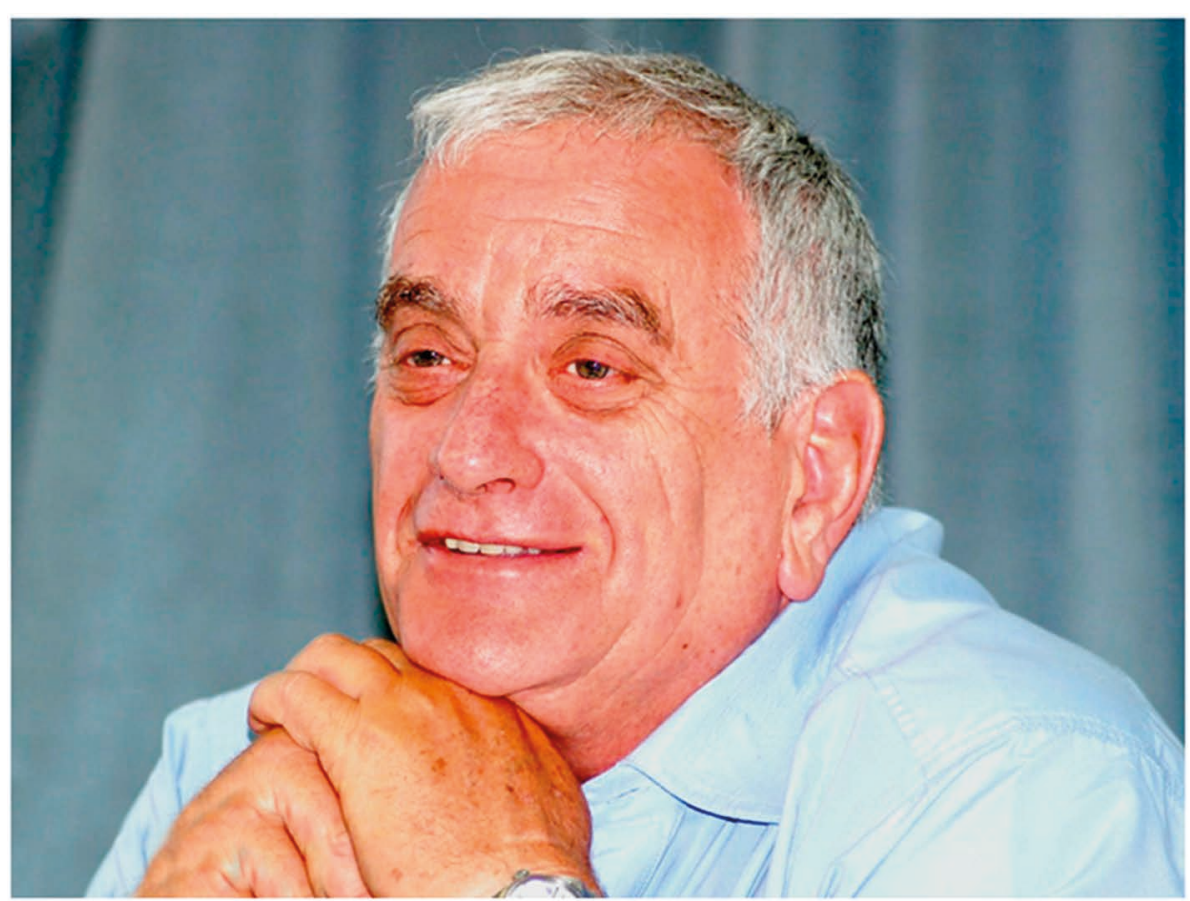

Assa was among the first people (in Israel) to light the beacon of medical computing as early as the late seventies, and ever since promoted the wide use of medical information systems. If there is someone in Israel who is entitled to be described as a "pioneer" and "breakthrough person"- this is certainly Assa.

Assa led and promoted the medical computing field from its early (and modest) initiatives all the way to the very advanced reality of today.

Assa was not only a wise person, professional, and bright, but also and mostly a person and a friend (a "Mensch" as it is said in Yiddish to designate a person of integrity and honor). He laid down the ground-breaking work of medical computing and was a teacher to many of us, who were exposed to this field.

Beyond his many personal activities, Assa devoted his life to the creation of a national platform for sharing and disseminating knowledge and experience among medical computing professionals. Indeed, Assa was among the founders of the Israeli Association for Medical Informatics, which also serves as such a platform. Together with a few enthusiasts, Assa was active for more than 30 years in the realization of the vision of knowledge sharing, and eventually witnessed the success of the association to unite hundreds of members and partners.

But Assa did not rest on his laurels and was keen to promote the Israeli medical computing field in the international community, initiating and establishing connections with leading international institutes and organizations.

Assa led the Israeli association to join EFMI and IMIA. His charm and personality soon brought about an international recognition of the Israeli association as well as the involvement of members of the Israeli association in the leaderships of international organizations.

As early as 1993, Assa was successful to convince EFMI to host MIE in Jerusalem. He served as the Israeli representative to EFMI, and in 2001, he was elected as EFMI president and served as president in the years 2002-2003.

Assa's vision has become a reality. Hundreds of experts, institutes, and organizations are invested in the promotion of medical computing in Israel. From an unpaved road, those activities have become a torrent that nowadays attract more and more experts and companies, and the Israeli association has become a central body for enrichment and knowledge exchange.

We, your friends and appreciators, are committed to sustain your legacy and continue promoting the activities of the Israeli association, both locally and abroad.

May we be blessed by your memory.

The Israeli Association for Medical Informatics (ILAMI)

Based on the funeral oration made by Haim Haklai, translated and edited by Amnon Shabo (Shvo) 